\title{
The Analysis of Hysteria
}

Second Edition

Understanding Conversion and Dissociation

By Harold Merskey

This book is a substantial update and enlargement of the first edition, which received exceptionally good reviews when first published in 1979. It provides a survey of the topics which have been included under the name of hysteria and which are still of importance under the terms conversion and dissociation. Current concepts of repression, including the common modern problems of "multiple personality disorder" and "recovered memory" are discussed in detail. The whole range of hysterical phenomena is covered, from classical paralyses and blindness to questions about hysterical personality and epidemic hysteria. $£ 30.00,486 p p$., Hardback, 1995, ISBN 0902241885

Gaskell is the imprint of the Royal College of Psychiatrists. Gaskell books are available from good bookshops and from the Publications Department, Royal College of Psychiatrists, 17 Belgrave Square, London SW1X 8PG (Tel. +44(0)171 235 2351, extension 146). The latest information on College publications is available on the INTERNET at: http://www.demon.co.uk/rcpsych/

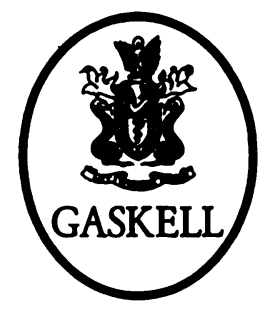

\section{Interpersonal Factors in Origin and Course of Affective Disorders}

\author{
Edited by Ch. Mundt, M.J. Goldstein, K. Hahlweg and P. Fiedler \\ with the assistance of Hugh Freeman
}

This detailed overview of the latest research on affective disorders brings together authors of international background and repute. Both a theoretical and practical approach to the origin and course of affective disorders is presented, covering specific problems and settings. The principal areas covered are: personality factors, risk and course; social support; marital and family interaction; and intervention. £30.00, 368pp., Hardback, 1996, ISBN 0902241907

Gaskell is the imprint of the Royal College of Psychiatrists. Gaskell books are available from good bookshops and from the Publications Department, Royal College of Psychiatrists, 17 Belgrave Square, London SW1X 8PG (Tel. +44(0)171 235 2351, extension 146). The latest information on College publications is available on the INTERNET at: http://wwrw.demon.co.uk/rcpsych/

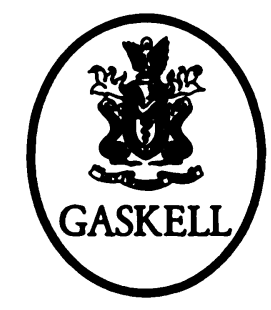




\section{O}

College Seminars

\section{Series from Gaskell}

\section{Seminars in}

\section{The Psychiatry of Learning Disabilities}

\section{Edited by Oliver Russell}

This volume is both an up to date account of recent advances in the field of learning disabilities and a practical guide to the diagnosis and treatment of psychiatric disorder. Chapters on the classification of psychiatric disorders in people with learning disabilities, the epidemiology of intellectual disability and the diagnosis of psychiatric disorder are followed by more detailed accounts of autism, behavioural phenotypes and communication disorders. Psychiatric disorders are covered in the latter part of the book, including discussions on behavioural interventions, counselling and epilepsy. The book concludes with a review of forensic aspects of psychiatric management and treatment.

Written primarily for trainee and general psychiatrists, this book will also be of use to consultants, paediatricians, nurses and social workers.

\section{7, 288pp, ISBN $0901242021, £ 15.00$}

Gaskell books are available from the Publications

Department, Royal College of Psychiatrists,

17 Belgrave Square, London SW1X 8PG

(Tel. +44(0)171 235 2351, extension 146).

The latest information on College publications is available on the INTERNET at: http://www.demon.co.uk/rcpsych/

\section{Epilim Oral Prescribing Information}

Presentation Epilim 200 Enteric Coated and Epilim 500 Enteric Coated: Enteric coated tablets containing $200 \mathrm{mg}$, and $500 \mathrm{mg}$ Sodium Valproate Ph.Eur. respectively. Epilim Crushable Tablets containing 100mg Sodium Valproate Ph.Eur. Epilim Syrup and Epilim Liquid (sugar free) both containing $200 \mathrm{mg}$ Sodium Valproate Ph.Eur. per 5ml. Epilim Chrono 200, Epilim Chrono 300, and Epilim Chrono 500: Controlled release tablets containing a mixture of Sodium Valproate $\mathrm{Ph}$.Eur. and Valproic Acid Fr.P. equivalent to $200 \mathrm{mg}, 300 \mathrm{mg}$, and $500 \mathrm{mg}$ Sodium Valproate respectively. Indications Oral formulations of Epilim are indicated for all types of epilepsy. In women of child bearing age Epilim should be used only in severe cases or in those resistant to other treatment. Dosage and administration Adults; the dose should be titrated at three day intervals until seizure control is achieved. Initially $600 \mathrm{mg}$ a day increasing in steps of $200 \mathrm{mg}$ to a maximum dose of $2500 \mathrm{mg}$ per day. Children over $20 \mathrm{~kg}$; initially $400 \mathrm{mg}$ a day increasing in steps to a maximum dose of $35 \mathrm{mg} / \mathrm{kg} /$ day. Children under $20 \mathrm{~kg}$; initially $20 \mathrm{mg} / \mathrm{kg} /$ day - the dose may be increased in severe cases provided that plasma levels are monitored; above $40 \mathrm{mg} / \mathrm{kg} /$ day chemistry and haematology should be monitored. Epilim Chrono may be given once or twice daily. All other formulations should be given twice daily. Combination therapy; levels of Epilim and co-administered anticonvulsants may be affected and optimum dosage is determined by seizure control. Contraindications, Warnings, etc. Contraindications Active liver disease, family history of severe liver disease, porphyria, hypersensitivity to valproate. Side effects Impaired hepatic function, particularly in children, occasionally leading to hepatic failure treatment should be withdrawn in patients who suddenly develop symptoms compatible with hepatic disease such as nausea, anorexia, jaundice or malaise. Hyperammonaemia with or without hepatic dysfunction. Blood dyscrasia - impaired platelet function, thrombocytopenia, occasional leucopenia, pancytopenia and red cell hypoplasia. Occasionally increased appetite, weight gain, transient hair loss, behavioural disturbances, hearing loss, vasculitis, alterations to the menstrual cycle and pancreatitis. Symptoms of intoxication include ataxia, tremor, and stupor. Drug interactions Epilim has significant interactions with phenytoin, lamotrigine and other anticonvulsants. Epilim may potentiate the effects of neuroleptics, MAOIs and other antidepressants, anticoagulants and salicylates. Cimetidine and erythromycin may inhibit the metabolism of Epilim. Mefloquine may decrease serum valproate levels. Epilim has no effect on the efficacy of oral contraceptives. Pregnancy An increased incidence of congenital abnormalities has been demonstrated in offspring born to mothers with epilepsy both untreated and treated, including those treated with sodium valproate. Neural tube defects have been reported in about $1-2 \%$ of offspring of women who have received valproate during the first trimester of pregnancy. Pregnancies should be screened for neural tube defects by estimation of alpha-fetoprotein and ultrasound. Folate supplementation has been shown to reduce the incidence of neural tube defects in the offspring of high risk women. Legal category P.O.M. Further information Epilim is hygroscopic - tablets should not be removed from their foil until they are used. Epilim Chrono is recommended in cases where plasma valproate levels are being measured on account of its pharmacokinetics. The effective therapeutic range for valproate is $40-100 \mathrm{mg} / 1$ (278-694 micromol/1). Product Licence Numbers Epilim 200 Enteric Coated 11723/0018, Epilim 500 Enteric Coated 11723/0020, Epilim 100mg Crushable Tablets 11723/0017, Epilim Syrup 11723/0025, Epilim Liquid 11723/0024, Epilim Chrono 200 11723/00 Epilim Chrono 300 11723/0021, Epilim Chrono 500 11723/0079. NHS Cost Ep

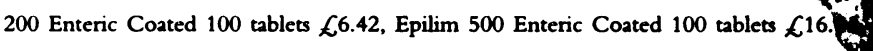

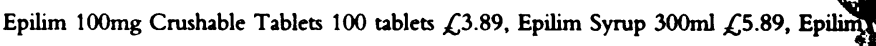
Liquid 300ml $f^{5.89}$, Epilim Chrono 200100 tablets $\chi^{7.70, \text { Epilim Chrono } 300100}$

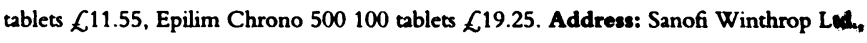
One Onslow Street, Guildford, Surrey GU1 4YS. Telephone: (01483) 505515 Fax: (01483) 35432. Epilim, Epilim Chrono and the Chrono device are registered trade marks. Date of preparation: January 1997.

\section{References:}

1. Chadwick D., J. Neurol. Neurosurg. Psychiatry 1994; 57: 264-277.

2. Gilham R.A., Epilepsy Res., 1990; 7: 219-225. 


\section{REASON TO BE CHEERFUL}

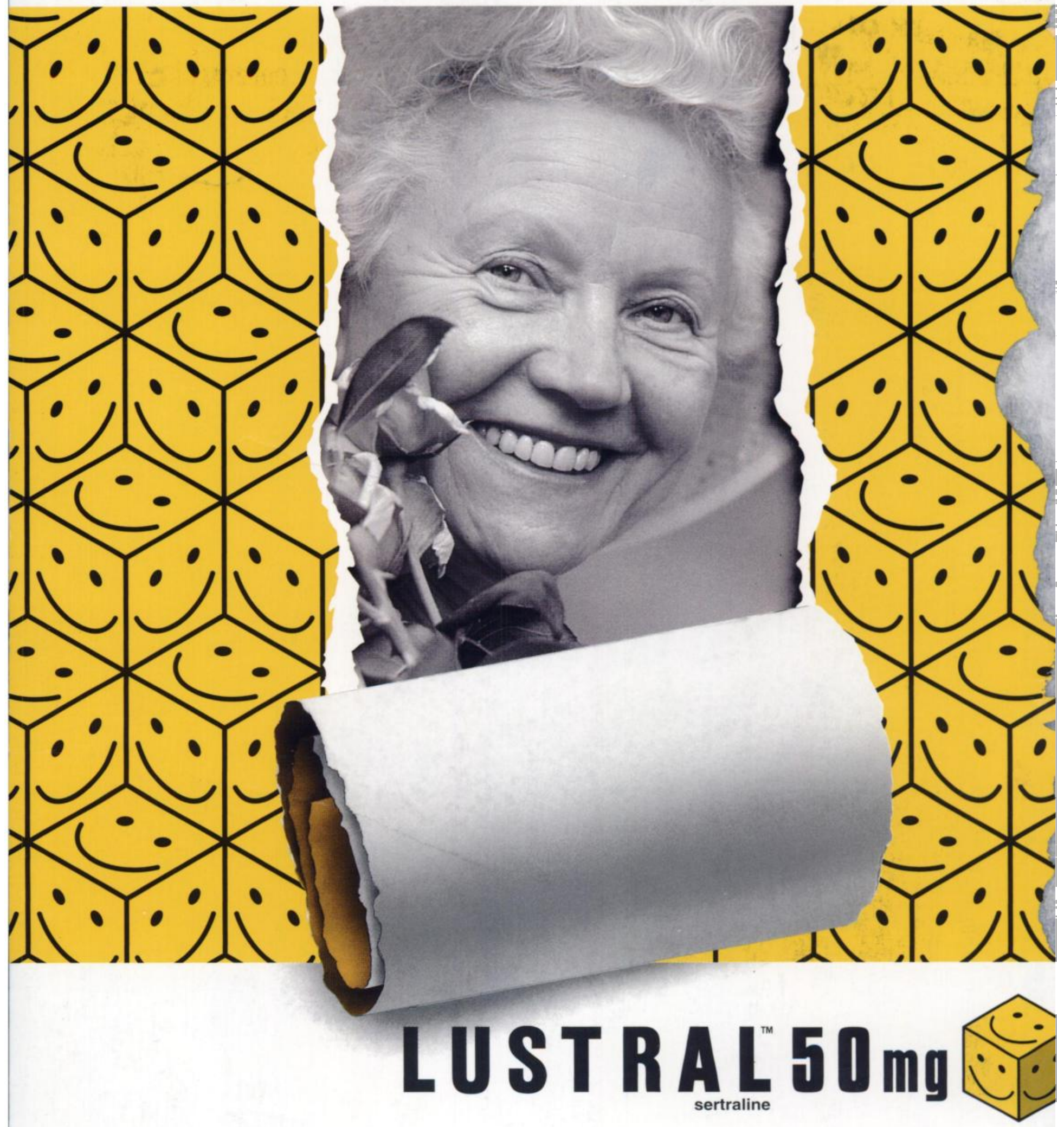

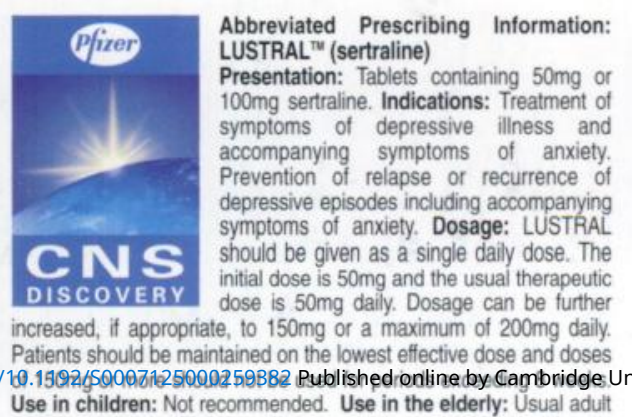

if clearly needed. Lactation: Not recommended. Precautions, warnings: Renal insufficiency, unstable epilepsy, ECT, driving. LUSTRAL should be discontinued in a patient who develops seizures. LUSTRAL should not be administered to patients concurrently being treated with tranquilizers who drive or operate machinery. Do not use with, or within two weeks of ending treatment with. MAOls. At least 14 days should elapse before starting any MAOI following discontinuation of LUSTRAL. Patients should be closely supervised for the possibility of suicide attempt or activation of maniahypomania. Drug interactions: Administer with caution in combination with other centrally active medication. Serotonergic drugs including tryptophan, sumatriptan and fenfluramine should not be used with LUSTRAL. It is recommended that plasma lithium levels be monitored following initiation of LUSTRAL. Although LUSTRAL has been shown to have no rsity Press eraction with alconol concomitant use with alcohot is not recommended. The potential for LUSTRAL to interact with other highly cimetidine has not been fully assessed. With warfarin prothro should be monitored when LUSTRAL is initiated or stoppe.. effects: Dry mouth, nausea, diarmhoealoose stools, ejaculatory tremor, increased sweating, dyspepsia, dizziness, insomnia somnolence. Asymptomatic elevations in serum transaminases seen reported intrequently (approx $0.8 \%$ ) in association LUSTRAL. These usually occurred within the first 9 weeks trea and resolved on cessation of therapy. Malaise and rash have reponted. Seizures (see precautions, wamings). There have isolated reports of movement disorders and rare case hyponatraemia. Legal category: POM. Basic NHS cost: $50 \mathrm{mg}$ (PL 570308) Calendar pack of 28, $226.51 ; 100 \mathrm{mg}$ tablet (PL 57) Calendar pack of 28, £39.77. Further information on request.

Invicta" Pharmaceuticals or

Richborough" Pharmaceuticals 


\section{Give someone with epilepsy a future to look forward to}

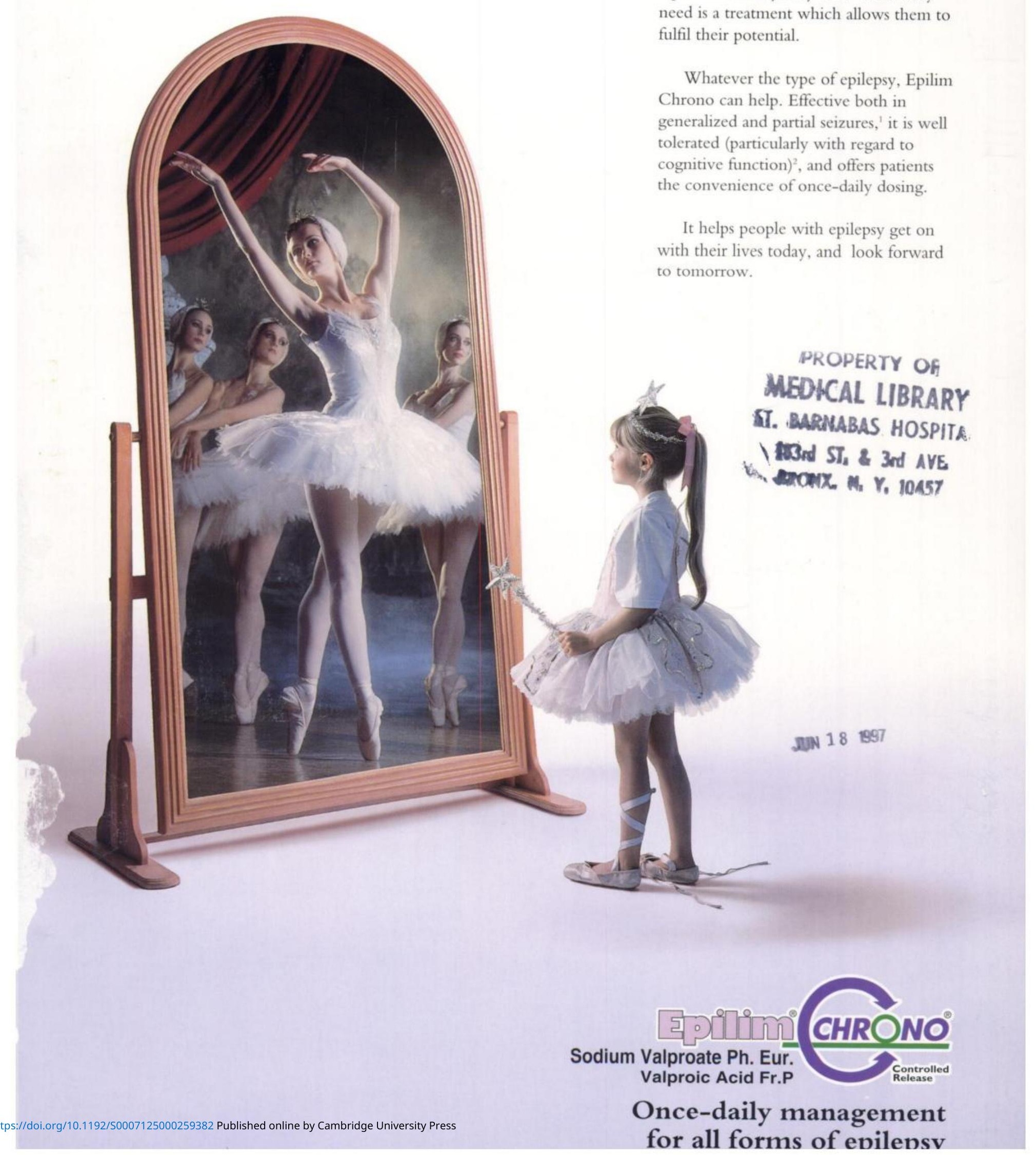

People with epilepsy have the same
aspirations as anybody else. What they
need is a treatment which allows them to
fulfil their potential. 